\title{
Analysis of the behavior of multijunction solar cells under high irradiance Gaussian light profiles showing chromatic aberration with emphasis on tunnel junction performance
}

Pilar Espinet-González' , Ignacio Rey-Stolle, Carlos Algora and Iván García

\begin{abstract}
In this work, we explain the behavior of multijunction solar cells under non-uniform (spatially and in spectral content) light profiles in general and in particular when Gaussian light profiles cause a photo-generated current density, which exceeds locally the peak current density of the tunnel junction. We have analyzed the implications on the tunnel junction's limitation, that is, in the loss of efficiency due to the appearance of a dip in the $I-V$ curve. For that, we have carried out simulations with our three-dimensional distributed model for multijunction solar cells, which contemplates a full description of the tunnel junction and also takes into account the lateral resistances in the tunnel junction. The main findings are that the current density photo-generated spreads out through the lateral resistances of the device, mainly through the tunnel junction layers and the back contact. Therefore, under non-uniform light profiles these resistances are determinant not only to avoid the tunnel junction's limitation but also for mitigating losses in the fill factor. Therefore, taking into account these lateral resistances could be the key for jointly optimizing the concentrator photovoltaic system (concentrator optics, front grid layout and semiconductor structure). Copyright (C) 2014 John Wiley \& Sons, Ltd.
\end{abstract}

KEYWORDS

tunnel junction; CPV; concentration; multijunction; solar cells; simulation; photovoltaics

\section{INTRODUCTION}

Photovoltaic concentrator optical designs must combine the following: (1) high geometric concentration; (2) high acceptance angle; (3) high irradiance uniformity; (4) high optical efficiency; and (5) low cost [1]. To fulfill these five requirements is a difficult task, and, to date, only partial solutions have been found [2]. Particularly, in regard to point 3 , solar concentrator optics often produce strongly inhomogeneous flux maps [3], which can cause a moderate loss in efficiency due to an increase of the effective series resistance, or even a drastic drop in efficiency if a dip in the $I-V$ curve appears because the local photo-generated current density exceeds the tunnel junction's (TJ) peak current density $[4,5]$. This last effect, namely the appearance of a dip in the $I-V$ curve under concentration, has been referred to TJ's limitation throughout this paper.
Many efforts have been carried out for making the light impinging the solar cell more uniform [6]. However, in regard to the TJ's limitation, it has been observed that under certain circumstances, the solar cell's short circuit current may be higher than the peak current of the TJ without causing an efficiency loss [4,7-9]. Accordingly, this paper seeks to first illustrate the behavior of multijunction solar cells under spatial and spectral non-uniform light profiles to finally clarify the real limitations imposed by $\mathrm{TJ}_{\mathrm{s}}$ in typical optical designs. For that, simulation with a three-dimensional (3D) distributed model developed for multijunction solar cells, which contemplates a full description of the TJ $[9,10]$, have been carried out. Most irradiance patterns produced by concentrator photovoltaic (CPV) optic systems produce an irradiance maximum at the center of the solar cell with decreasing irradiance toward the edges, and this decay is, in most of the 
conventional CPV imaging optics, well approximated by a Gaussian curve [11]. Then, in this paper, the behavior of a multijunction solar cell and the TJ's limitation when different Gaussian light profiles impinge the solar cell have been analyzed.

\section{DESCRIPTION OF THE THREE- DIMENSIONAL DISTRIBUTED CIRCUIT MODEL USED}

The 3D distributed model used in this paper has been explained in detail elsewhere [9]. In brief, the approach followed consists in dividing the solar cell into elementary units and assigning a suitable circuit model to each unit, depending on its geometry and position in the solar cell area (shadowed, illuminated or perimeter). The complete solar cell can subsequently be modeled by an electrical circuit that is obtained by interconnecting every elementary unit with its neighbors through the lateral resistances. The resulting equivalent circuit formed by thousands of elements is solved by using the Simulation Program with Integrated Circuit Emphasis (SPICE) circuit simulator. It has to be pointed out that the validation of the 3D distributed model to be able to simulate triple-junction solar cells under real conditions, including non-uniform irradiance profiles and chromatic aberration have been presented in [12]

In this study, for the sake of clarity, a dual-junction $(2 J S C)(\mathrm{GaInP}) /(\mathrm{GaAs})$ solar cell was used as the test vehicle for the simulations. This device has a single $\mathrm{TJ}$; thus, the interpretation of the results and their implications are clearer than for a triple junction solar cell.

The equivalent circuits that describe the three kinds of elementary units in the dual-junction solar cell simulated are depicted in Figure 1.

The model takes into account the tunnel diode definition by including a full description of its $\mathrm{J}-\mathrm{V}$ characteristics. In this paper, the complete static J-V characteristic of the tunnel diode junction has been modeled by using the following analytical expressions [13]:

$$
\begin{gathered}
J_{T \jmath}(V)=J_{t}(V)+J_{x}(V)+J_{t h}(V) \\
J_{t}(V)=J_{p}\left(V / V_{p}\right) \exp \left(1-V / V_{p}\right) \\
J_{X}(V)=J_{V} \cdot \exp \left[A\left(V-V_{V}\right)\right] \\
J_{t h}(V)=J_{0}[\exp (q V / k T)-1]
\end{gathered}
$$

where $J_{T J}$ is the current density of the TJ; $J_{t}$ is the tunneling current density; $J_{X}$ is the excess current density; $J_{t h}$ is the thermal current density; $J_{p} V_{p}, J_{V} V_{V}$ and $A$ are constants, which determine the peak and valley currents and voltages of the TJ detailed in Figure $2 ; J_{0}$ is the recombination current density; and the other parameters have their standard meaning.
Also, the lateral current distribution through the layers which make up the TJ has been taken into account in the model by introducing the lateral resistors ( $R_{\text {Anode }}$ and $R_{\text {Cathode }}$ in Figure 1) [10]. It has to be pointed out that a similar approach has been followed by Steiner et al in [14], and the integration of TJ characteristics into the network model was validated by comparison of simulated and experimental data.

The 2JSC characteristics used in this paper are based on a specific device [15]. Briefly, the device is a high concentrator GaInP/GaAs solar cell with an active area of $1 \mathrm{~mm}^{2}$ and a front metal grid featuring an inverted square configuration that is comprised of eight evenly spaced fingers that are $3 \mu \mathrm{m}$ wide, producing a shadowing factor of $2.7 \%$, surrounded by a busbar that is $100 \mu \mathrm{m}$ wide (see details in [15]). In order to simplify the interpretation of the simulations presented in this paper, it is assumed that both subcells are current matched at a short-circuit current density of $13.5 \mathrm{~mA} / \mathrm{cm}^{2}$ at 1 sun. The J-V characteristic of the TJ used in the simulations is depicted in Figure 2. We decided not to use the real TJ of these devices (based on $\mathrm{AlGaAs} / \mathrm{GaAs}$ heterostructure) [15] because its peak tunneling current is so high that its effects become negligible for concentrations below 20,000 suns [16]. Instead, we decided to use the TJ depicted in Figure 2. It should be noted that the value of the peak current density $\left(J_{\text {peak }}\right.$ in this TJ $\left(40.5 \mathrm{~A} / \mathrm{cm}^{2}\right)$ is equivalent to an irradiance of $3000 \mathrm{X}$ in our test device. In summary, the simulated device includes the top (TC) and bottom (BC) cells features described previously [15], together with the TJ sketched in Figure 2.

\section{ANALYSIS OF MULTIJUNCTION SOLAR CELL PERFORMANCE UNDER SPATIALLY AND SPECTRAL NON-UNIFORM IRRADIANCE}

Refractive concentrating optics cause flux distributions that are spatially non-uniform, not only in absolute irradiance but also in spectral content. Also, in the case of the concentrator optics system constituted only by a Fresnel lens without any secondary optics, a Gaussian light profile is a good approximation of the light pattern produced by the lens. Thus, in this study, the 2JSC has been simulated when the subcells are impinged by different Gaussian light profiles in order to study the impact of not only non-uniform light profiles in irradiance levels but also in spectral content on the behavior of a multijunction solar cell and on the TJ's limitation. About the spectral distribution, when the solar cell is closer to the lens than its design position, the peak to average ratio (PAR) of the Gaussian light profile of the blue light that is used by the TC (GaInP) is higher than the PAR of the flux distribution of the red light used by the $\mathrm{BC}$ (GaAs). However, when the cell is farther to the lens than its design position, the spectral content of the flux distribution is the opposite one; the $\mathrm{BC}$ receives a Gaussian light profile with a PAR higher than the PAR of 


\section{Perimeter}

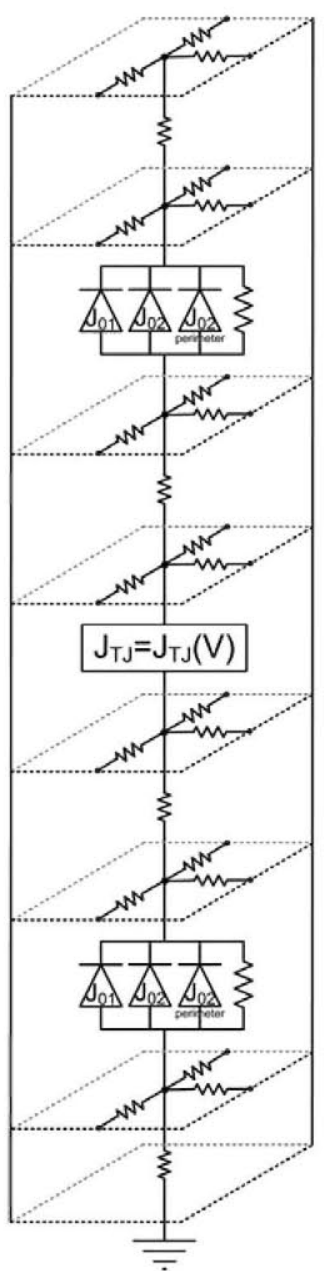

Metalized

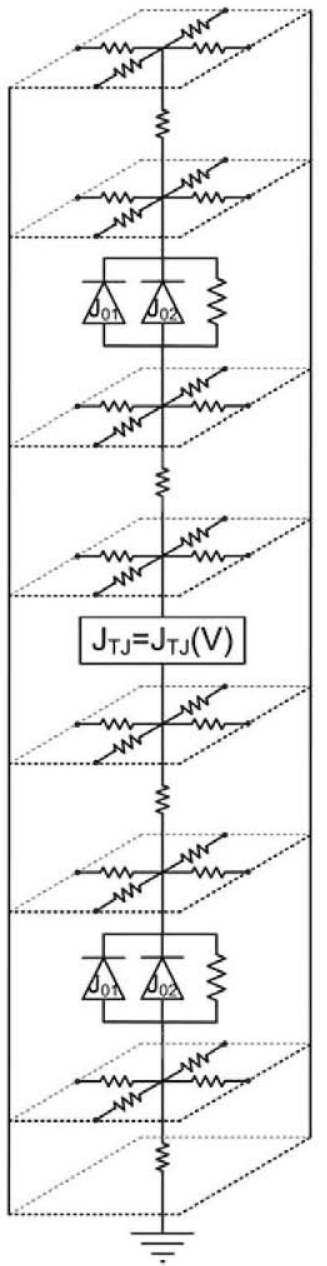

\section{Illuminated}

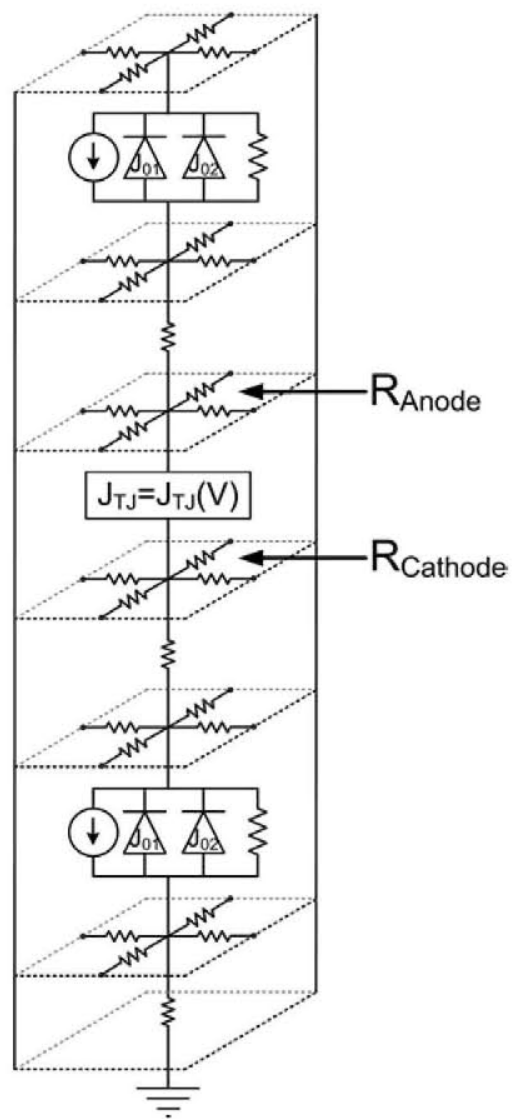

Figure 1. From left to right, the elementary unit cell of a perimeter area, dark area and illuminated area of a dual junction solar cell are presented. In this advanced model, the tunnel junction is modeled with a component represented by an analytical expression and lateral resistances ( $R_{\text {Anode }}$ and $\left.R_{\text {Cathode }}\right)$ [10].

the Gaussian light profile used by the TC [17]. In order to analyze the impact of these situations, two different light profiles have been simulated (Figure 3):

- A Gaussian light profile with a peak of $4000 \mathrm{X}$ and average $1000 \mathrm{X}$ in the TC (that is, $\mathrm{PAR}_{T C}=4$ ) and a Gaussian light profile with a peak of $2000 \mathrm{X}$ and average $1000 \mathrm{X}$ in the $\mathrm{BC}\left(\mathrm{PAR}_{B C}=2\right)$, from now on referred as case a).

- A Gaussian light profile with a peak of $2000 \mathrm{X}$ and average $1000 \mathrm{X}$ in the TC $\left(\mathrm{PAR}_{T C}=2\right)$ and a Gaussian light profile with a peak of $4000 \mathrm{X}$ and average $1000 \mathrm{X}$ in the $\mathrm{BC}\left(\mathrm{PAR}_{B C}=4\right)$, from now on referred as case b).

The $I-V$ curves resulting from the simulations are depicted in Figure 4. In both situations (case a, blue solid line and case $b$, red solid line), no dip-related effects are apparent. However, for the two light profiles studied (cases $a$ and b) the tolerance to a high irradiation peak is not the same. In fact, the dip in the $I-V$ curve appears at a PAR of 4.2 in the TC (with a PAR of 2 in the BC). This result is not shown in Figure 4 for the sake of clarity, but it has been obtained from the simulations. In the case of the $\mathrm{BC}$, no dip-related effects are revealed, even for a PAR as high as 10. In fact, not only their impact on the TJ's limitation is different in both cases but also the fill factor $(F F)$ and the efficiency are noticeably different in both situations.

The disparity in the 2JSC behavior in Figure 4 is determined by the value of the lateral resistance through which the excess of photo-generated current is spread out. In order to study the influence of the TJ lateral resistances in both Gaussian light profiles simulated (case a and case b), simulations increasing the value of $R_{\text {Anode }}$ and $R_{\text {Cathode }}$ have been carried out (black lines in Figure 4). Further, we will discuss the different behaviors for a 


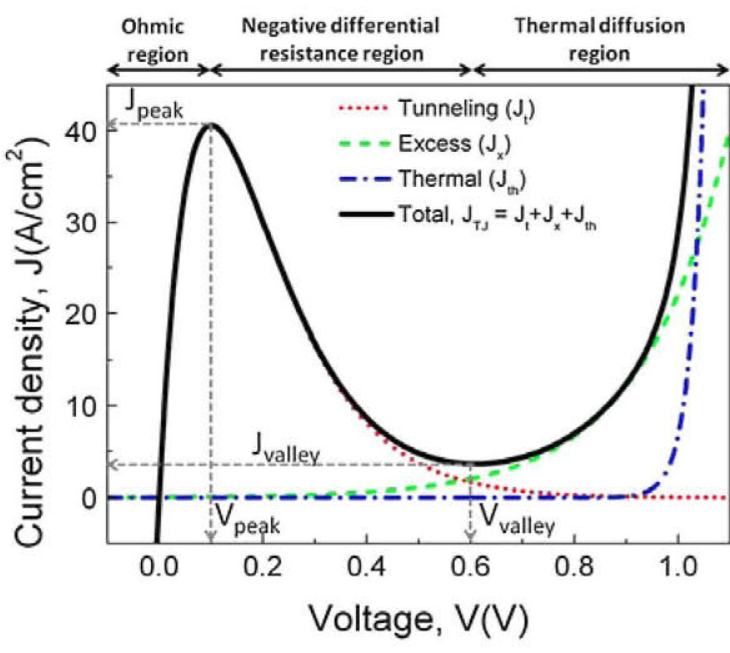

Figure 2. J-V Characteristic of the tunnel junction used in the simulations presented in this paper. The characteristic parameters of the $J-V$ curve appear as labels in the figure: peak current density $\left(J_{\text {peak }}=40.5 \mathrm{~A} / \mathrm{cm}^{2}\right)$, peak voltage $V_{\text {peak }}=(0.1 \mathrm{~V})$, valley current density $\left(J_{\text {valley }}=3.6 \mathrm{~A} / \mathrm{cm}^{2}\right)$ and valley voltage $\left.V_{\text {valley }}=0.6 \mathrm{~V}\right)$.

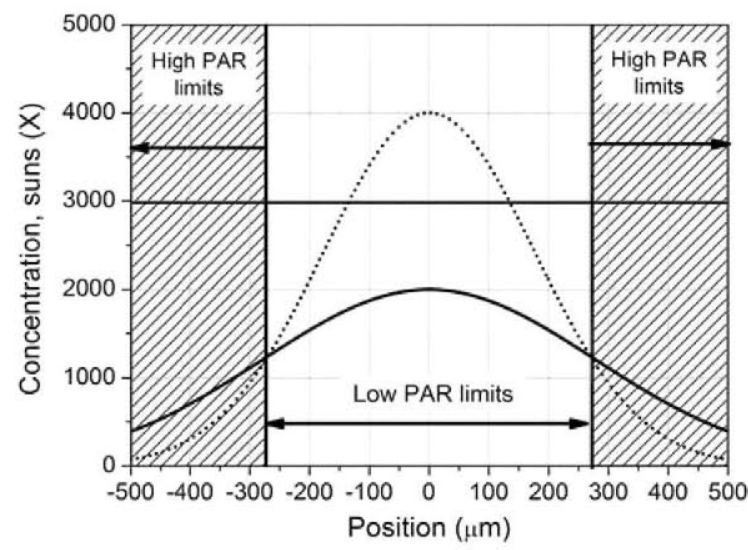

Figure 3. Gaussian light profiles simulated, with peaks of 4000 $X$ and $2000 X$ over the average of $1000 \mathrm{X}$ in both cases.

voltage bias in the 2.JSC $\left(V_{2 J S C}\right)$ of $V_{2 J S C}=0 \mathrm{~V}$ and at $V_{2 J S C}=2.15 \mathrm{~V}$, when case a is already in the 'knee' of the $I-V$ curve, whereas case $\mathrm{b}$ is still in the flat region of the $I-V$ curve.

In these kind of light patterns (Figure 3), the Gaussian light profile with a peak of $4000 \mathrm{X}$ produces a higher light flux in the center of the solar cell, whereas the Gaussian light profile with a peak of $2000 \mathrm{X}$ produces a higher light flux at the borders. Then, as both subcells photo-generate a higher current density than the other subcell, either in the center or at the border of the solar cell, we are not able to predict at $V_{2 J S C}=0 \mathrm{~V}$ which subcell has the diodes forward biased and which one has the diodes reverse biased to fulfill $V_{2 J S C}=$ $V_{T C}-V_{T J}+V_{B C}$. In Figure 5, the false color maps

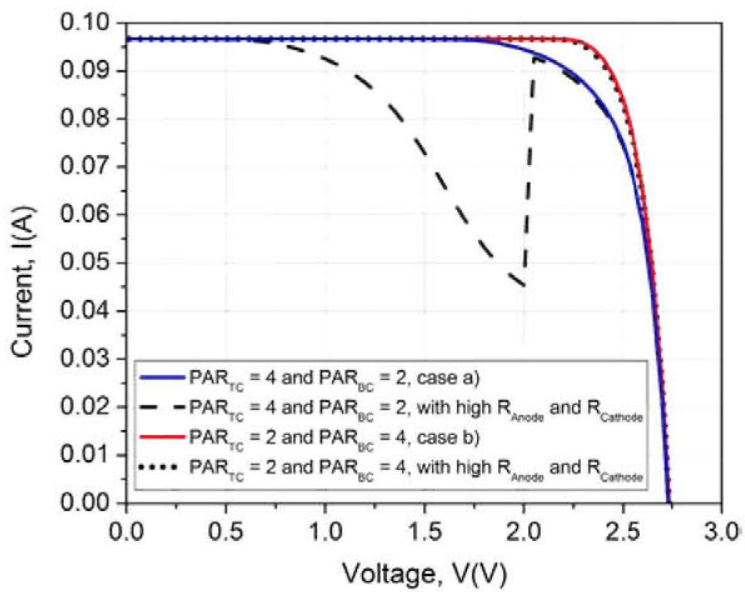

Figure 4. $I-V$ curves of the dual-junction solar cell under Gaussian light profiles with different peak to average ratio (PAR) in each subcell. The blue line represents the 2JSC's $1-V$ curve in case $a$. The red line depicts case $b$. The dashed black line represents the case a but for high values of $R_{\text {Anode }}$ and $R_{\text {Cathode }}$ and the dotted black line depicts case $\mathrm{b}$ for high values of $R_{\text {Anode }}$ and $R_{\text {Cathode }}$.

that represent the voltage drop in each junction at short circuit are shown. It has to be noted that the voltage drop in the junctions is considered positive when the recombination diodes are reverse biased and negative when they are forward biased, that is, when they are draining current density. Then, from Figure 5, it can be deduced that the subcell that is impinged by the Gaussian light profile with a peak of $2000 \mathrm{X}$ is the one whose diodes are forward biased (negative voltage drop), whereas the diodes of the subcell impinged by the Gaussian light profile with a peak of $4000 \mathrm{X}$ are reverse biased (positive voltage drop). Therefore, the subcell impinged by the Gaussian light profile with PAR $=2$ is the one which is draining some of the photo-generated current at short circuit condition.

\subsection{Analysis of case a $\left(\operatorname{PAR}_{T C}=4\right.$ and $\mathbf{P A R}_{B C}=2$ )}

In this case, the excess of current density photo-generated in the center of the solar cell is not drained by the TC diodes, because they are reverse biased (or forward biased but at a very low voltage value; Figure 5(a)). As such, the current density that is photo-generated in the center of the solar cell flows through the TC vertical resistances toward the anode of the TJ. There, the current density is spread out through $R_{\text {Anode }}$ [9] toward the borders of the solar cell making it possible for the TJ to work in the ohmic region (Figure $5(\mathrm{c})$ ). It has to be pointed out that at the borders the TJ is working in the third quadrant (gray scale in Figures 5(c) and 6(c)). In $\mathrm{R}_{\text {Cathode }}$ and in the lateral resistance of the $\mathrm{BC}$ emitter, the current density spreads 


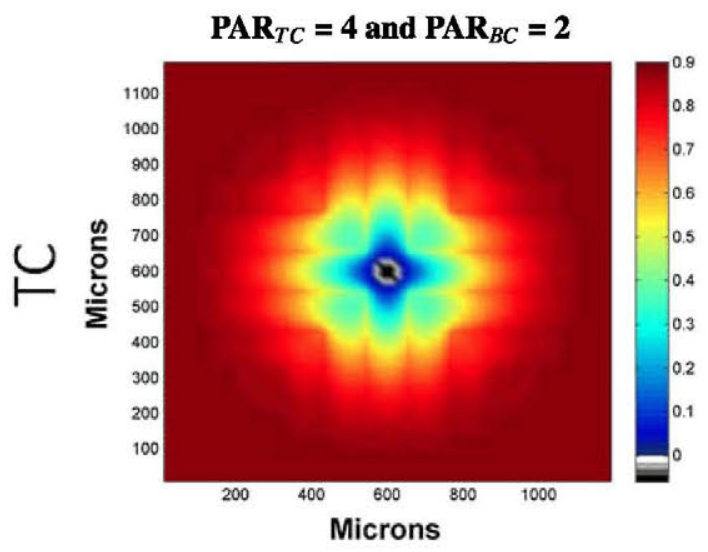

(a)

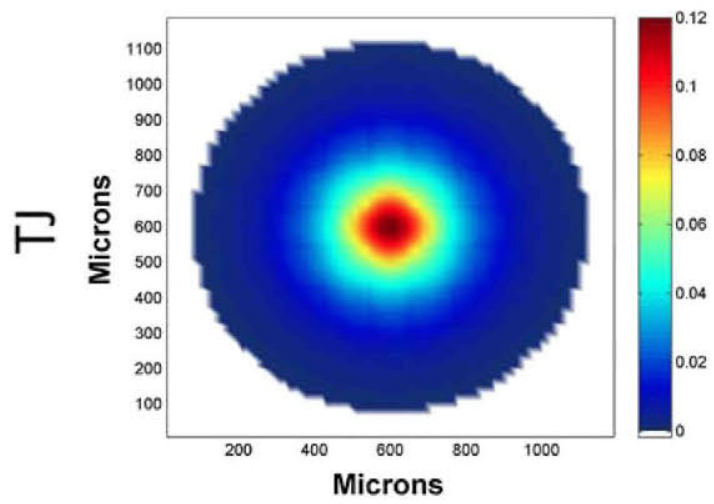

(c)

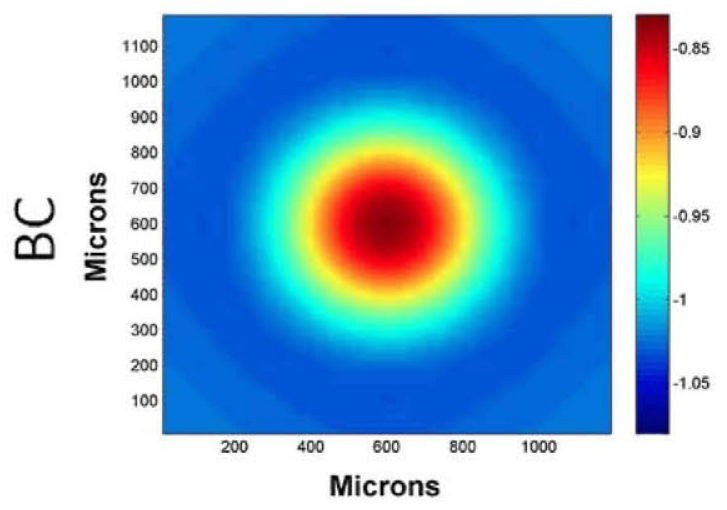

(e)

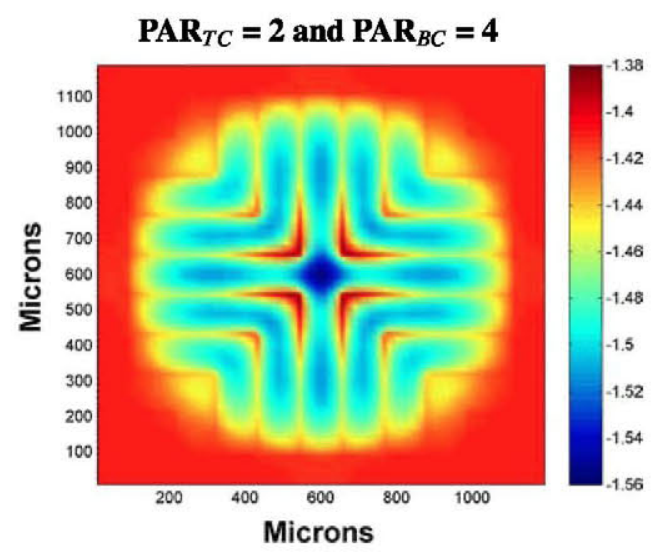

(b)

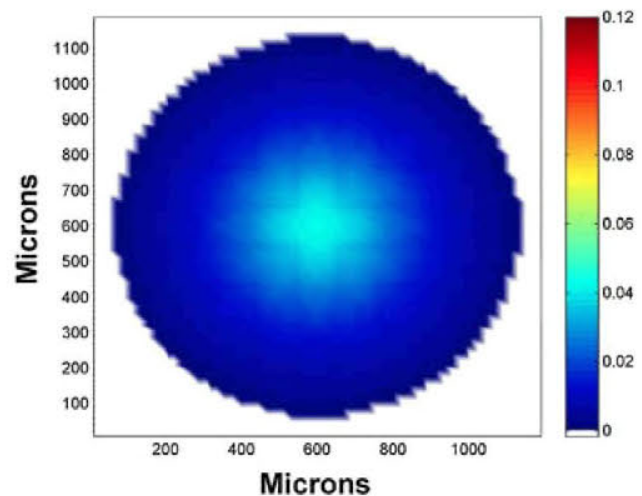

(d)

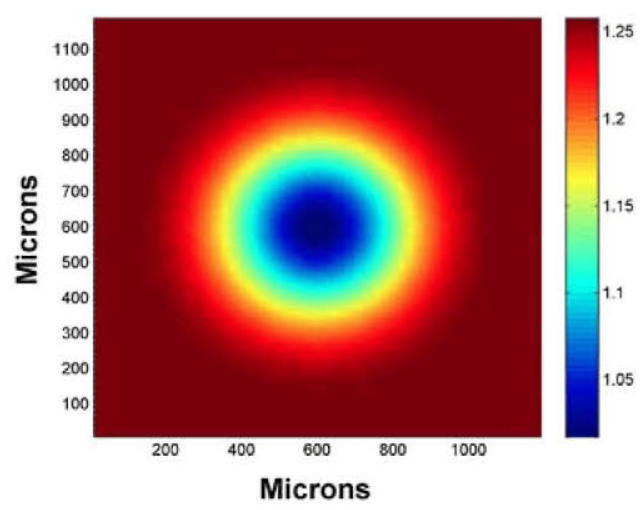

(f)

Figure 5. False color maps of the voltage drop (V) through the top cell (TC; (a) and (b)), the tunnel junction (TJ; (c) and (d)) and the bottom cell (BC; (e) and (f)) at short-circuit current $\left(\mathrm{V}_{2 J S C}=0 \mathrm{~V}\right)$ with standard values of $R_{\text {Anode }}$ and $R_{\text {Cathode }}$ in case a (left figures) and in case $b$ (right figures). Areas represented with the gray scale denote regions where the voltage drop occurs in the opposite direction than in the rest of the solar cell. Please note that the voltage drop in the junctions is considered positive when the recombination diodes are reverse biased and negative when they are forward biased (see details in the text). 


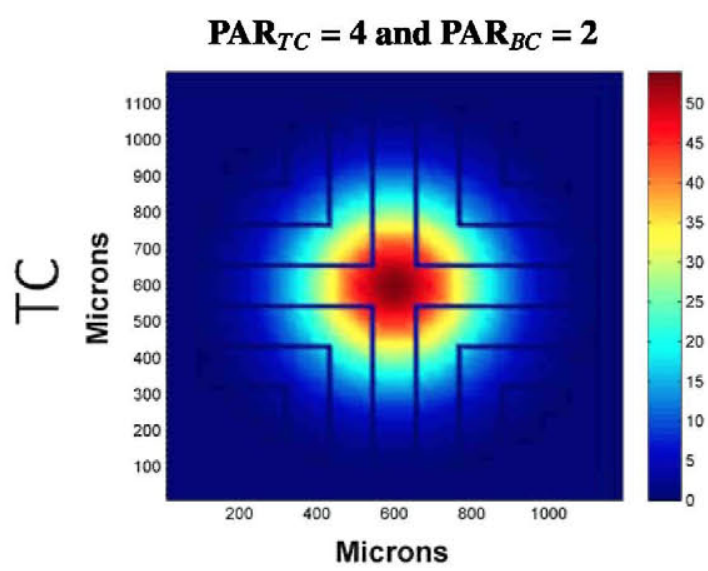

(a)

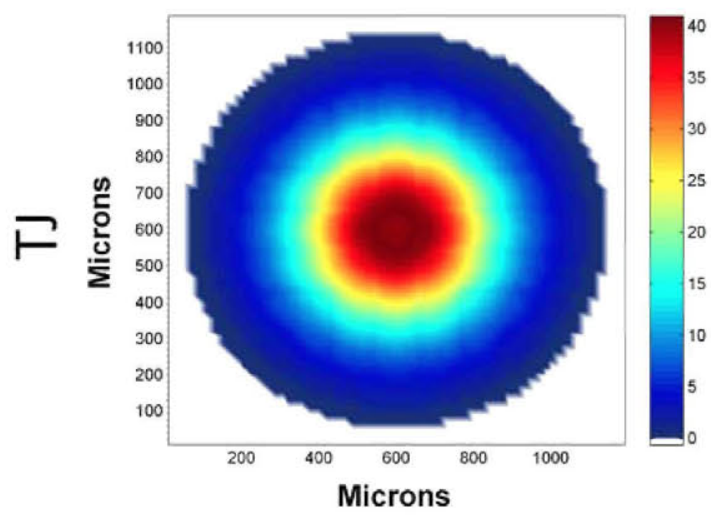

(c)

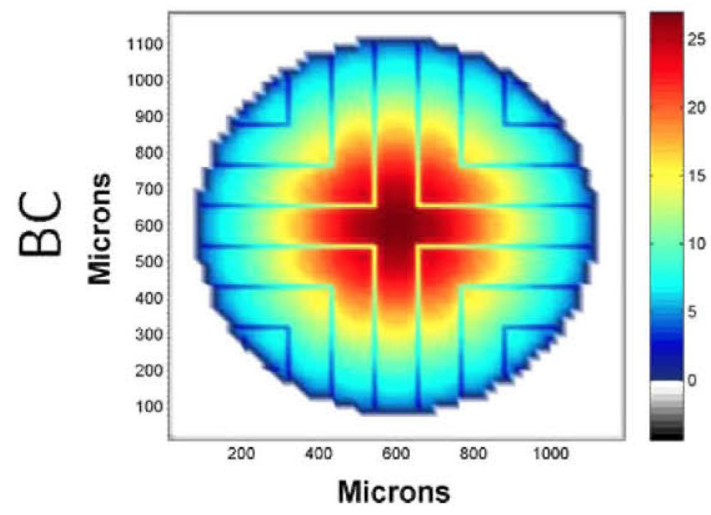

(e)

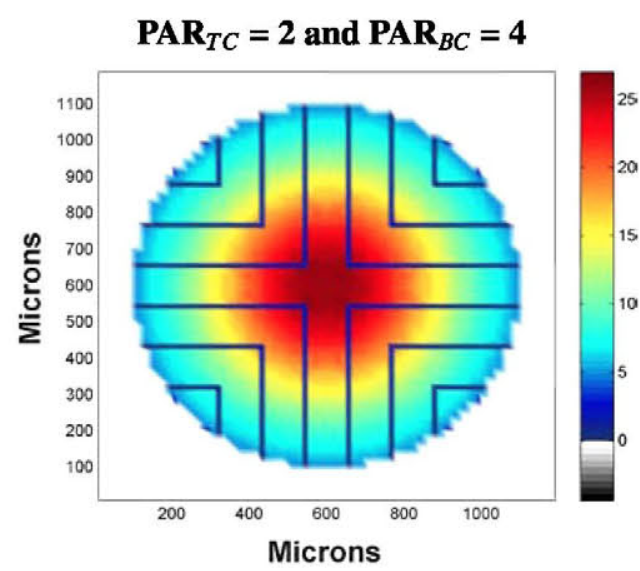

(b)

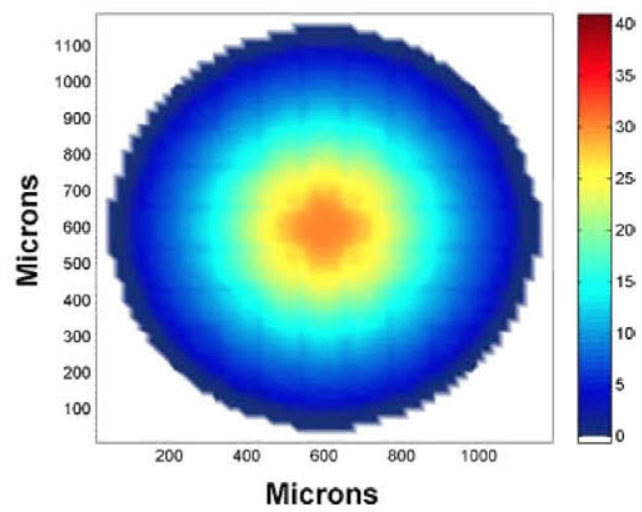

(d)

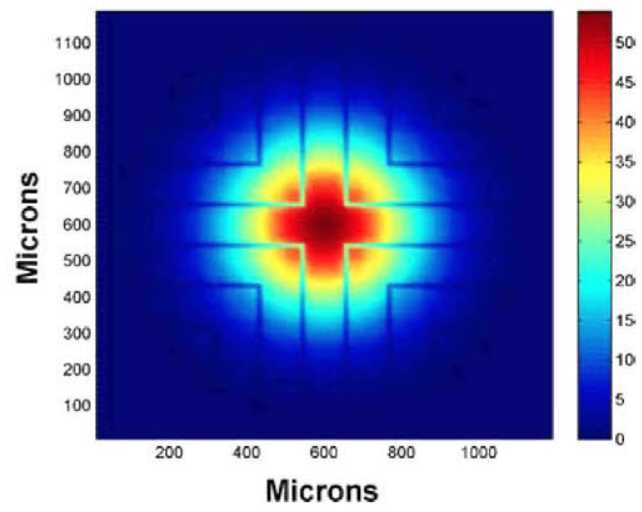

(f)

Figure 6. False color maps of the current density $\left(A / \mathrm{cm}^{2}\right)$ through the vertical resistance of the top cell (TC; (a) and (b)), the tunnel junction ( $\mathrm{TJ} ;(\mathrm{c})$ and $(\mathrm{d}))$ and the bottom cell $(\mathrm{BC})$ vertical resistance $((\mathrm{e})$ and $(\mathrm{f}))$ at short-circuit current $\left(V_{2} / S C=0 \mathrm{~V}\right)$ with standard values of $R_{\text {Anode }}$ and $R_{\text {Cathode }}$ in case a (left figures) and in case b (right figures). Areas represented with the gray scale denote regions where the current flows in the opposite direction, that is, upwards instead of downwards. 


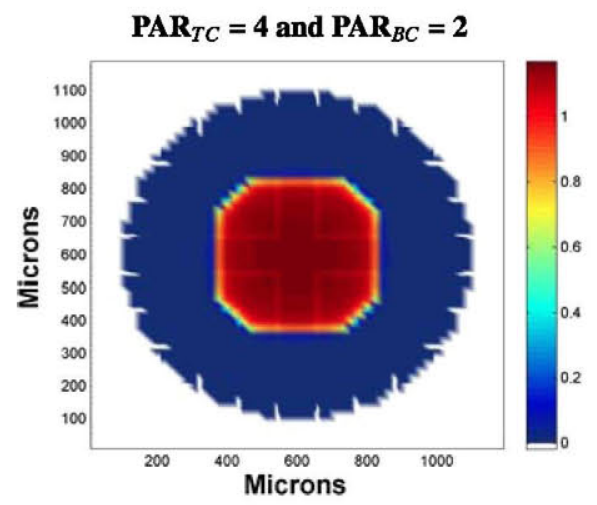

(a)

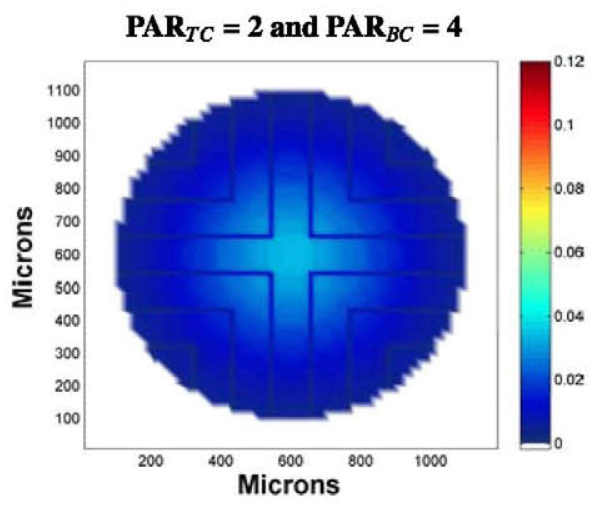

(b)

Figure 7. False color maps of the voltage drop in the TJ when the values of the $R_{\text {Anode }}$ and $R_{\text {Cathode }}$ are very high at short-circuit current $\left(\mathrm{V}_{2 J S C}=0 \mathrm{~V}\right)$ in case a $(\mathrm{a})$ and in case $\mathrm{b}(\mathrm{b})$. Please note that the voltage drop in the junctions is considered positive when the recombination diodes are reverse biased and negative when they are forward biased (see details in the text).

more through the borders of the solar cell to reproduce the Gaussian light profile with peak $2000 \mathrm{X}$, which impinges the $\mathrm{BC}$ [18]. The diodes of the $\mathrm{BC}$ are forward biased, and the voltage drop is higher in the borders (Figure 5(e)). Then, some of the photo-generated current is drained through them and more significantly at the perimeter (Figure 6(e)). It has to be noted that in this case, the capability of $R_{\text {Anode }}$ to spread current density is close to its limit because the current density through TJ equals its peak current density $\left(J_{\text {peak }}=40.5 \mathrm{~A} / \mathrm{cm}^{2}\right)$ in the center of the solar cell (Figure 6(c)). In fact, as mentioned before, at a peak of $4200 \mathrm{X} \pm 100 \mathrm{X}$ in the $\mathrm{TC}$, the spreading of photo-generated current density through the $R_{\text {Anode }}$ is not enough, and the TJ has to work in the thermal diffusion region, consequently a dip in the $I-V$ curve appears [9]. Also, if now we assume high values of $R_{\text {Anode }}$ and $R_{\text {Cathode }}$ for $\mathrm{PAR}_{T C}=4$ and $\mathrm{PAR}_{B C}=2$, $R_{\text {Anode }}$ is not able to spread the excess of the photogenerated current density generated in the center of the TC. Therefore, the tunnel junction works in the thermal diffusion region (Figure 7(a)), so the current density photogenerated in the center of the TC (higher than $40.5 \mathrm{~A} / \mathrm{cm}^{2}$ ) flows through it, and as expected, a dip in the $I-V$ curve appears (Figure 4).

At $V_{2 J S C}=2.15 \mathrm{~V}$, the $I-V$ curve is in the "knee" region (Figure 4). The decrease of current is because of the TC diodes which were reverse biased at short-circuit condition (positive voltage drop, Figure 5(a)), at $2.15 \mathrm{~V}$ are forward biased (negative voltage drop, Figure 8(a)), and their voltage drop is high enough to make them drain photo-generated current density. Consequently, the overall current of the 2JSC decreases. In Figure 8, the false color maps represented with a sepia scale denote subcells which were reverse biased at short-circuit current and are forward biased at $2.15 \mathrm{~V}$. The decrease of current through the TC vertical resistance in the center of the solar cell is appreciated when comparing the false color maps at the short-circuit condition (Figure $6(\mathrm{a})$ ) and at $V_{2 J S C}=2.15 \mathrm{~V}$ (Figure 9(a)).

\subsection{Analysis of case $b\left(\operatorname{PAR}_{T C}=2\right.$ and $\operatorname{PAR}_{B C}=4$ )}

In this case, the excess of current density photo-generated in the center of the $\mathrm{BC}$ is spread out through the back contact [18], which is modeled as a short circuit. Then, in this case, the role of $R_{\text {Anode }}$ and $R_{\text {Cathode }}$ is modest.

At short-circuit condition, the TC diodes are forward biased so they are draining some of the photo-generated current, mainly in the center of the solar cell (Figure 5(b)). The photo-generated current density, which is not drained flows through the vertical TC resistance toward the anode of the TJ. There, the current is slightly spread toward the center of the solar cell, but the current density which flows through the TJ is considerably smaller than the TJ peak current density (Figure 6(d)). Then, the TJ works in the ohmic region in the whole area of the solar cell (Figure 5(d)); consequently, the dip in the $I-V$ curve does not appear [9]. In $R_{\text {Cathode }}$ and the lateral resistance of the $\mathrm{BC}$ emitter, the current density spreads toward the center of the solar cell reproducing the light pattern produced by the Gaussian light profile with $4000 \mathrm{X}$ in the BC. At high values of $R_{\text {Anode }}$ and $R_{\text {Cathode, }}$ the TJ keeps working in the ohmic region in the center and in the third quadrant at the borders (Figure 7(b)), and it only leads to a slight decrease in FF (Figure 4). It has to be pointed out that in the 2JSC simulated, a high value of $R_{\text {Anode }}$ is equivalent to an open circuit; however, a high value of $R_{\text {Cathode }}$ has a negligible impact on the equivalent circuit of the solar cell because it is basically connected in parallel with the lateral resistance of the $\mathrm{BC}$ emitter, which is lower than the standard $R_{\text {Cathode. }}$ Therefore, in this case for high $R_{\text {Anode }}$ and high $R_{\text {Cathode, }}$ the current through the TJ will reproduce the light pattern in the $\mathrm{TC}$, and it will be spread out through the lateral resistance of the $\mathrm{BC}$ emitter to reproduce the light pattern in the $\mathrm{BC}$.

At $V_{2 J S C}=2.15 \mathrm{~V}$, the $I-V$ curve is still in the "flat" region of the $I-V$ curve (Figure 4 ). This is so because 


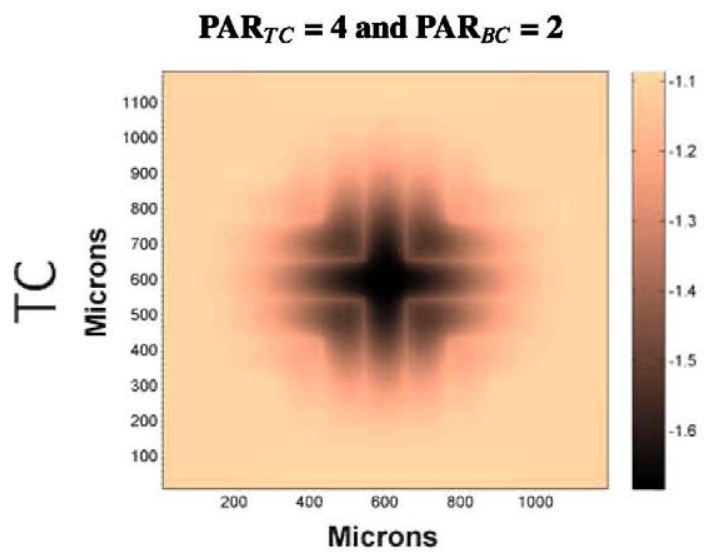

(a)

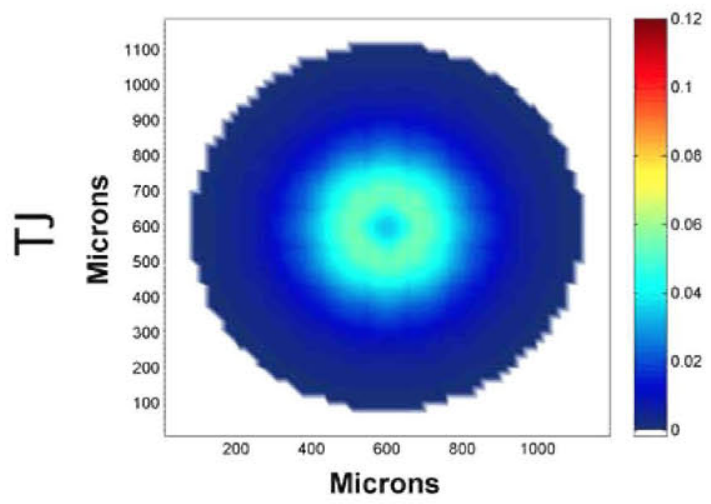

(c)

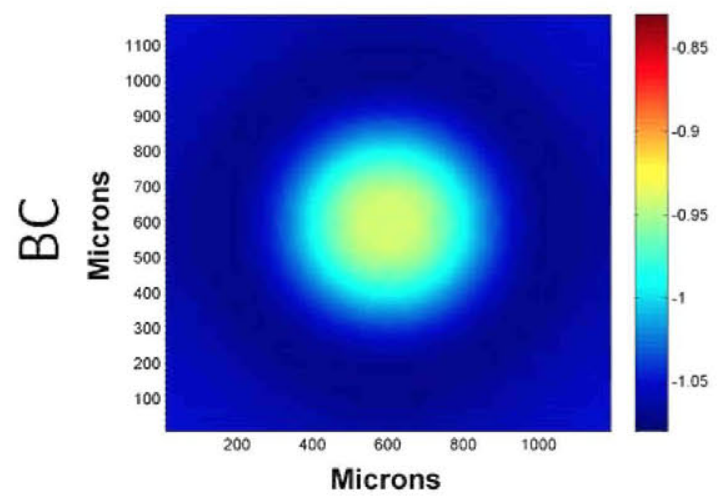

(e)

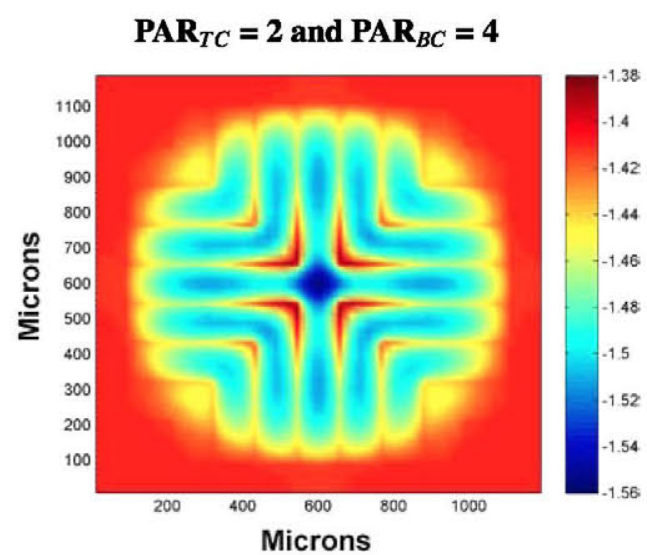

(b)

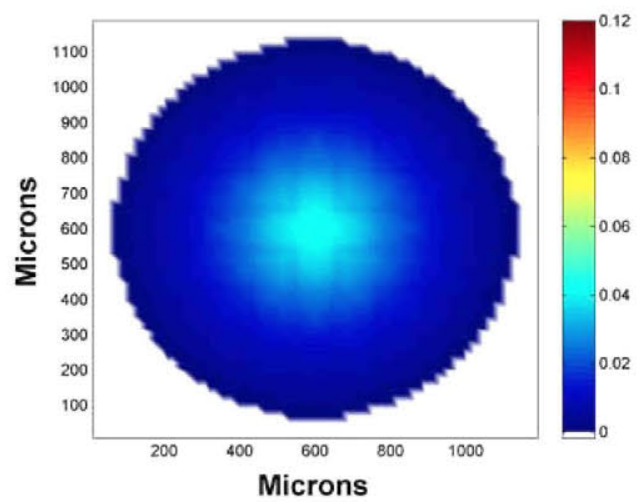

(d)

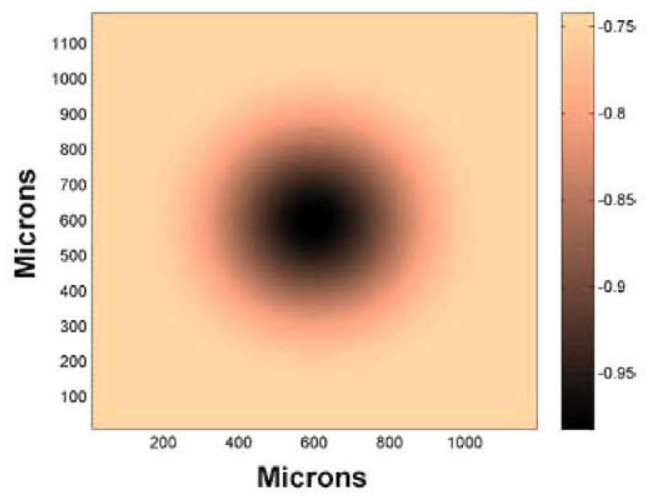

(f)

Figure 8. False color maps of the voltage $\operatorname{drop}(\mathrm{V})$ through the top cell (TC; (a) and (b)), the tunnel junction (TJ; (c) and (d)) and the bottom cell $(\mathrm{BC} ;(\mathrm{e})$ and $(\mathrm{f}))$ at $V_{2 J S C}=2.15 \mathrm{~V}$ with standard values of $R_{\text {Anode }}$ and $R_{\text {Cathode }}$ in case a (left figures) and in case b (right figures). Sepia false color maps denote that the subcell diodes are forward biased at $2.15 \mathrm{~V}$, and they were reverse biased at $0 \mathrm{~V}$. Areas colored in white denote regions where the voltage drop occurs in the opposite direction than in the rest of the solar cell. Please note that the voltage drop in the junctions is considered positive when the recombination diodes are reverse biased and negative when they are forward biased (see details in the text). 


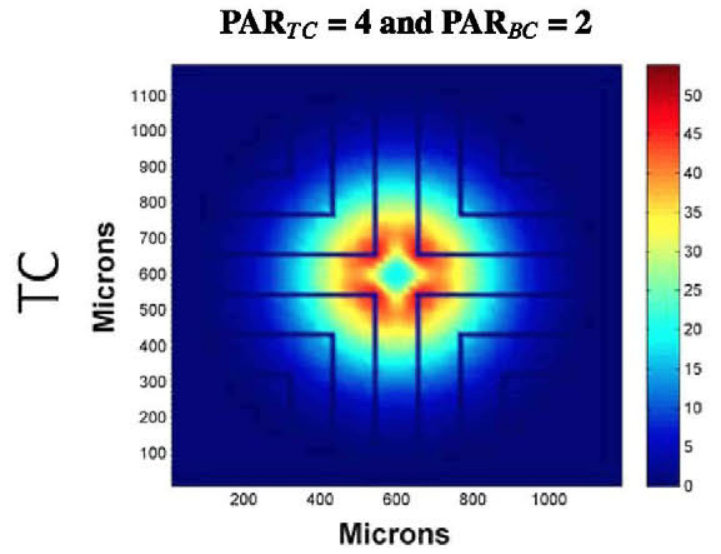

(a)

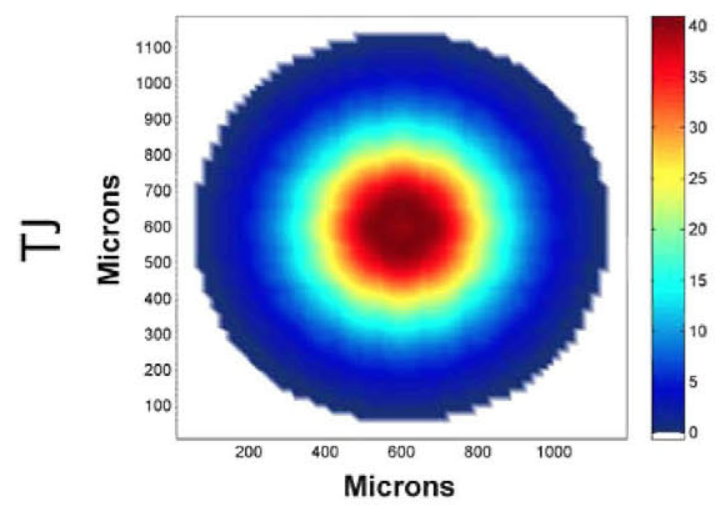

(c)

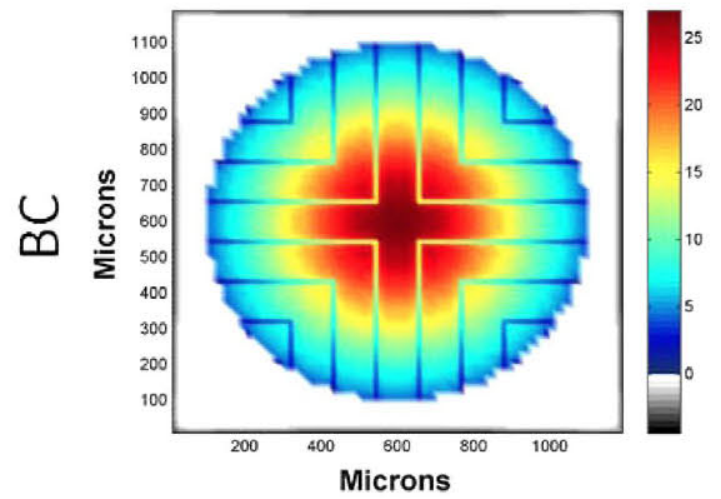

(e)

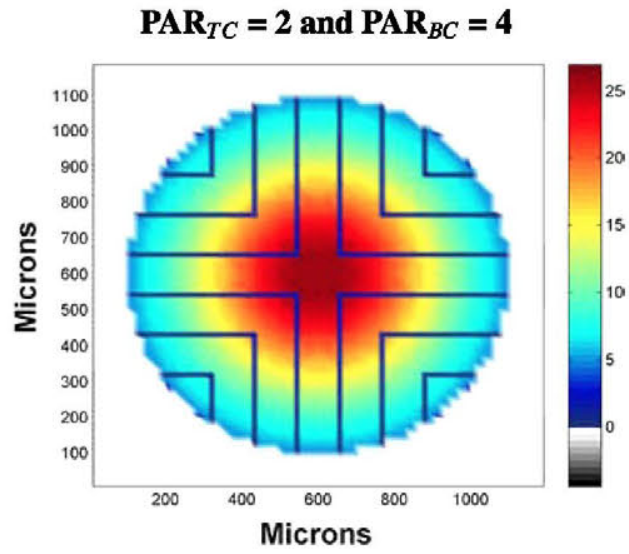

(b)

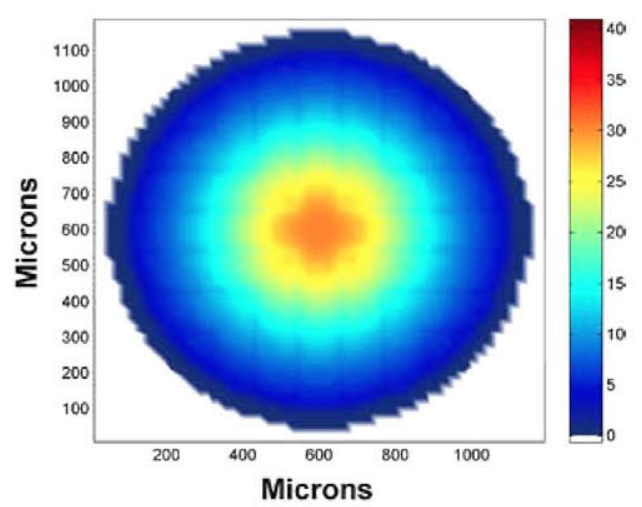

(d)

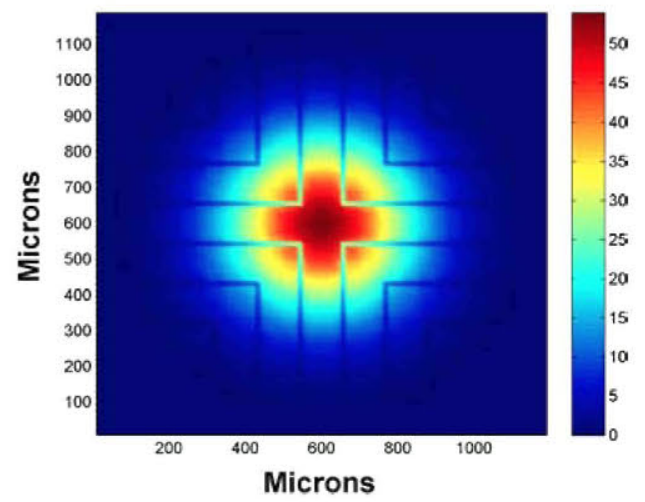

(f)

Figure 9. False color maps of the current density $\left(\mathrm{A} / \mathrm{cm}^{2}\right)$ through the vertical resistance of the top cell (TC; (a) and (b)), the tunnel junction ( $\mathrm{TJ}$; (c) and (d)) and the bottom cell $(\mathrm{BC})$ vertical resistance $((\mathrm{e})$ and $(\mathrm{f}))$ at $V_{2 J S C}=2.15 \mathrm{~V}$ with standard values of $R_{\text {Anode }}$ and

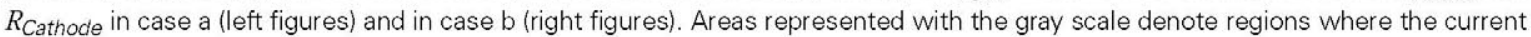
flows in the opposite direction, that is, upwards instead of downwards. 
the $\mathrm{BC}$ diodes, which were reverse biased at short circuit (Figure 5(f)), at $2.15 \mathrm{~V}$ are forward biased (Figure 8(f)). However, the voltage drop in the $\mathrm{BC}$ diodes is not high enough to make them significantly drain photo-generated current density (the false color maps of the current density through the vertical resistances of the $\mathrm{BC}$ at short-circuit condition (Figure 6(f)) and at $V_{2} J S C=2.15 \mathrm{~V}$ (Figure 9(f)) are identical). As a result, the overall current of the 2JSC does not change.

These relevant effects have to be taken into account by the concentrator optics designers. Therefore, in this particular dual-junction, designers should favor that in case of Gaussian-kind non-uniformities due to either the concentrator design or misalignments in the CPV system or changes in the spectrum (throughout the day, throughout the year or due to changes in temperature), the highest peak of the Gaussian light profile impinges on the BC instead of on the TC.

\section{PRELIMINARY RESULTS IN A TRIPLE-JUNCTION SOLAR CELL}

In order to have an idea about if the general findings in a 2JSC could be directly extrapolated to triple-junction solar cells (3JSC), simulations of a 3JSC with the same parameters than the 2JSC for the GaInP TC and the GaAs middle cell (MC) but including an extra TJ and the germanium subcell, have been carried out. Also, the TJ that connects the GaInP TC and the GaAs MC has the same characteristics than the one used in the simulations of the 2JSC (Figure 2). However, for the sake of clarity, the TJ that interconnects the $\mathrm{GaAs} \mathrm{MC}$ and the $\mathrm{Ge} \mathrm{BC}$ has a peak current density much higher $\left(J_{\text {peak }}=150 \mathrm{~A} / \mathrm{cm}^{2}\right)$. In the 3JSC, both TJs can be made of different semiconductor materials; consequently, both TJs can have pretty different characteristics.

In order to analyze the impact of the same non-uniform light profiles on a 3JSC, two light profiles have been simulated:

- The TC is impinged by a Gaussian light profile with peak of $4000 \mathrm{X}$ on an average of $1000 \mathrm{X}$ (PAR =4) and the $\mathrm{MC}$ and the $\mathrm{BC}$ with a Gaussian light profile with peak of $2000 \mathrm{X}$ on an average of $1000 \mathrm{X}$ (PAR = 2).

- The TC is impinged by a Gaussian light profile with a PAR $=2$ and the $\mathrm{MC}$ and $\mathrm{BC}$ by a Gaussian light profile with a $\mathrm{PAR}=4$.

In Figure 10 , the $I-V$ curves obtained in both light profiles simulated are depicted. Again, no dip in the $I-V$ curve is observed in any case even though the current density photo-generated in the center of one subcell (TC or $\mathrm{MC}$ ) is higher than the peak current density of the top TJ. Also, the same general result is observed, the impact of the non-uniformities on the $\mathrm{TC}$ are more relevant than on the MC showing both $I-V$ curves, a significant difference in FF. This behavior, totally alike to what was shown

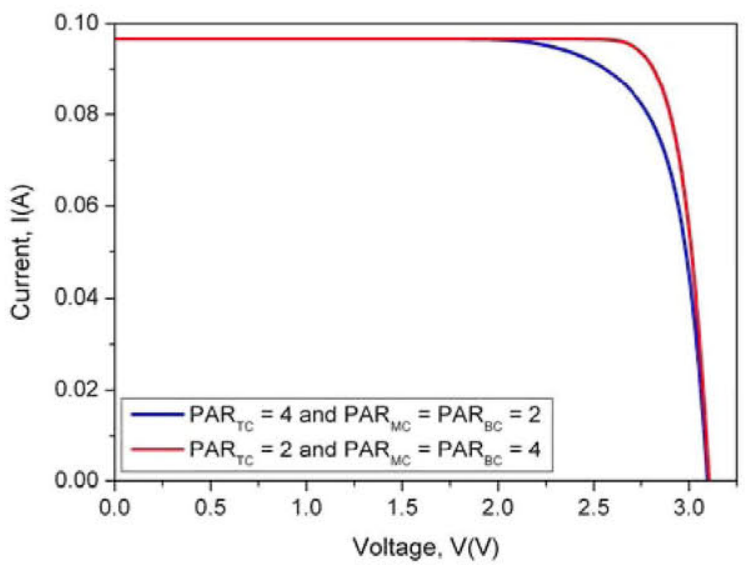

Figure 10. $I-V$ curves of the triple-junction solar cell under Gaussian light profiles all of them with the same average of $1000 \mathrm{X}$ but different peaks: $4000 \mathrm{X}(\mathrm{PAR}=4$ ) or $2000 \mathrm{X}$ $(P A R=2)$.

in Figure 4 for the 2JSC, can be again explained as the result of an asymmetric lateral current redistribution capability in the structure (higher in the $\mathrm{MC} / \mathrm{BC}$ and lower in the TC).

\section{SUMMARY AND CONCLUSIONS}

In this paper, we have simulated Gaussian light profiles in order to analyze the behavior of a multijunction solar cell under non-uniform light profiles and to study their impact on the TJ's limitation, on the multijunction solar cell efficiency and on the concentrator optics design. The simulations have been carried out with our 3D distributed model. The main conclusions extracted from the simulations of the different Gaussian light profiles have been the following:

(1) The current density photo-generated in the subcells spreads out through the lateral resistances, mainly $R_{\text {Anode, }}, R_{\text {Cathode }}$ and the back contact.

(2) The dip in the $I-V$ curve occurs when the current spreading through the lateral resistances at shortcircuit condition is insufficient to maintain the whole $\mathrm{TJ}$ working in the ohmic region.

(3) The lateral resistances are determinant not only for the TJ's limitation but also for mitigating the loss in efficiency due to non-uniformities.

(4) High non-uniformities in the TC are smoothed by $R_{\text {Anode }}$ and $R_{\text {Cathode. }}$

(5) High non-uniformities in the BC are smoothed by the back contact.

(6) Under non-uniform light profiles, some areas of the $\mathrm{TJ}$ can be forward biased and others reverse biased.

(7) Non-uniform light profiles on the BC (in a 2 JSC)/MC (in a 3JSC) can be significantly less adverse for the overall working of the multijunction solar cells than non-uniform light profiles on the TC. 


\section{ACKNOWLEDGEMENTS}

This work was supported by the European Commission under the project NGCPV "A new generation of concentrator photovoltaic solar cells, modules and systems" with Grant agreement no. 283798. The Spanish Ministerio de Economía y Competitividad has also contributed with the projects TEC2011-28639-C02-01, TEC2012-37286, IPT2011-1441-920000, and IPT-2011-1408-420000, as well as the Comunidad de Madrid under the NUMANCIA II program (S2009/ENE1477).

\section{REFERENCES}

1. Benítez P, Miñano JC. Concentrator optics for the next-generation photovoltaics in next generation photovoltaics, Ch. 13., Institute of Physics, 2004.

2. Benítez $\mathrm{P}$, Miñano JC, Zamora $\mathrm{P}$, Mohedano $\mathrm{R}$, Cvetkovic A, Buljan M, Chaves J, Hernández M. High performance Fresnel-based photovoltaic concentrator Optics Express 2010; 18(210): 25-40.

3. Victoria M, Domínguez C, Antón I, Sala G. Comparative analysis of different secondary optical elements for aspheric primary lenses. Optics Express 2009; 17(8): 6487-6492.

4. Andreev V, Ionova E, Larionov V, Rumyantsev V, Shvarts M, Glenn G. Tunnel diode revealing peculiarities at I-V measurements in multijunction III-V solar cells, In Conference Record of the 2006 IEEE 4th World Conference on Photovoltaic Energy Conversion, Waikoloa, HI, Vol 1, 2006; 799-802. DOI: 10.1109/WCPEC.2006.279577

5. Guter W, Bett AW. I-V characterization of tunnel diodes and multijunction solar cells. IEEE Trans Electron Devices 2006; 53(9): 2216-2222.

6. Winston R, Miñano J, Benítez P. Nonimaging Optics. Elsevier: Burlington, MA, USA, 2005.

7. Espinet P, Garcia I, Rey-Stolle I, Algora C, Baudrit, M. Distributed simulation of real tunnel junction effects in multi-junction solar cells, In Proceedings of the 6th International Conference on Concentrating Photovoltaic Systems, CPV-6, AIP, American Institute of Physics, Freiburg, Germany, Vol 1277, 2010; 24-27.

8. Braun A, Hirsch B, Katz EA, Gordon JM, Guter W, Bett AW. Localized irradiation effects on tunnel diode transitions in multi-junction concentrator solar cells Solar Energy Materials and Solar Cells 2009; 93(9): 1692-1695.

9. Espinet P, García I, Rey-Stolle I, Algora C, Baudrit M. Extended description of tunnel junctions for distributed modeling of concentrator multijunction solar cells. Solar Energy Materials and Solar
Cells 2011; 95(9): 2693-2697, DOI: 10.1016/j.solmat. 2011.05.009. http://www.sciencedirect.com/science/ article/pii/S0927024811002662, Available online 1 June 2011.

10. Método implementado en computador para la simulación numérica de un dispositivo semiconductor que comprende uniones túnel, patent pending EP10382076.7, (April 2010).

11. Herrero R, Victoria M, Domínguez C, Askins S, Antón I, Sala G. Concentration photovoltaic optical system irradiance distribution measurements and its effect on multi-junction solar cells. Progress in Photovoltaics: Research and Applications 2012; 20(4): 423-430, DOI: 10.1002/pip.1145. http://dx.doi.org/10.1002/pip. 1145, Available online 29 August 2011.

12. García I, Espinet P, Rey-Stolle I, Barrigón E, Algora C. Extended triple-junction solar cell 3D distributed model: application to chromatic aberration-related losses, In Proceedings of the 7th International Conference on Concentrating Photovoltaic Systems, CPV-7, AIP, American Institute of Physics, Las Vegas, USA, Vol 1407, 2011; 13-16.

13. Sze SM. Physics of Semiconductor Devices, 2nd Edition. Wiley: New York, 1981.

14. Steiner M, Guter W, Peharz G, Philipps SP, Dimroth F, Bett AW. A validated spice network simulation study on improving tunnel diodes by introducing lateral conduction layers. Progress in Photovoltaics: Research and Applications 2012; 20(3): 274-283, DOI:10.1002/pip.1133. http://dx.doi. org/10.1002/pip.1133, Available online 21 July 2011.

15. García I, Rey-Stolle I, Galiana B, Algora C. A 32.6\% efficient lattice-matched dual-junction solar cell working at 1000 suns. Applied Physics Letters 2009; 94(5): 053509 .

16. García I, Rey-Stolle I, Algora C. Performance analysis of $\mathrm{AlGaAs} / \mathrm{GaAs}$ tunnel junctions for ultra-high concentration photovoltaics. Journal of Physics D: Applied Physics 2012; 45(4): 045101.

17. Victoria $M$, Herrero R, Domínguez C, Antón I, Askins S, Sala G. Characterization of the spatial distribution of irradiance and spectrum in concentrating photovoltaic systems and their effect on multi-junction solar cells. Progress in Photovoltaics: Research and Applications 2013; 21(3): 308-318, DOI:10.1002/pip.1183. http://dx.doi.org/10.1002/pip. 1183, Available online 19 October 2011.

18. Espinet-González P. Advances in the modeling, characterization and reliability of concentrator multijunction solar cells. Ph.D. Thesis, Technical University of Madrid (UPM), 2012. 